\title{
Investigation on Static Stress Analysis of Portal Axle Gearbox
}

\author{
Devan P D ${ }^{1}$, Senthilkumar K $\mathbf{M}^{2}$ \& Arun K K ${ }^{3}$ \\ Department of Mechanical Engineering, Kumaraguru College of Technology, Coimbatore, India.
}

\begin{abstract}
.
The paper deals with stress analysis of spur gear used in portal axle gearbox. Portal axle is a type of gearbox, especially used in off-road vehicles. Gear teeth failure takes place due to excessive contact and bending stresses. Three different configurations of gear trains have taken for the analysis. Gear trains are modeled and assembled in SOLIDWORKS and analyzed in ANSYS workbench 14.5 software. Steel, Cast Iron and Aluminium Alloy are taken as gear materials. In this study, contact and bending stresses are theoretically calculated using Hertzian theory and Lewi's formula and simulated using finite element method (FEM). The theoretical stress values are compared with simulation results. Both simulation and theoretical results have good agreement with each other. From the results, it could be concluded that gearbox with two ideal gears provides $50 \mathrm{~mm}$ more ground clearance than the gearbox without ideal gear. Among three materials aluminium alloy experiences, $30 \%$ to $40 \%$ reduced stress values.
\end{abstract}

Keywords: portal axle, contact stress, finite element analysis, bending stress, ANSYS workbench

\section{INTRODUCTION}

Portal axle is developed with a gearbox at the end of the axle housing that drops the wheel centre under the axle tube for extra ground clearance. The hub gears permits the axle to drive with reduced torque and constant power. It decreases the load on the differential and crown wheel. Schematic diagram of normal and portal axle is showed in the fig. 1

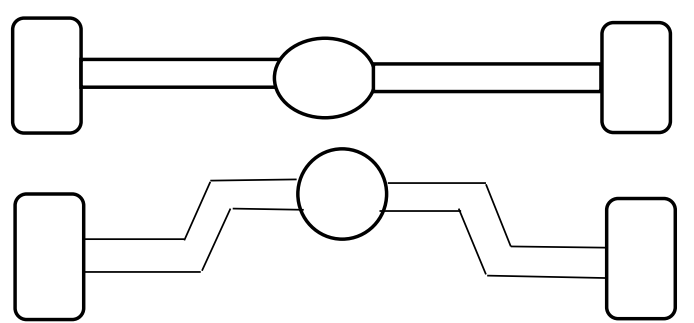

Figure 1. Normal and Portal axle

In off-road driving, portal axles are frequently subjected to shock and overloading. It may lead to failure of the gearbox. Therefore, gears in the portal axle must be designed with the extremely high strength to obtain performance. Spur gear is widely used for large power transmission. Since teeth of the spur gear is parallel to the axis, its efficiency and power rating is more. It can be used at vast range of speed ratio. Gear failure can occur in various modes. Scoring, wear, pitting, plastic flow, and tooth fracture are the common modes of gear failure. Due to cyclic loading, a pit is formed on the gear tooth surface and leads to surface failure. After a longer period, crack is initiated at root fillet. Tooth breakage occurs when the bending stress exceeds the maximum limit.

Contact stress is a kind of surface failure modes of the gear tooth due to repetitive fatigue load. In static analysis, entire load is acting on the single tooth. In a dynamics analysis, theses stresses at pitch circle is less than other areas [1]. Shuting Li [2] has develop an accurate analytical method to find out bending and contact stress of a spur gear tooth with the consideration of Mechanical, Assembly and Transmission errors. It is reported that $\mathrm{ME}, \mathrm{AE}$ and $\mathrm{TM}$ predominantly affects the stress development. The influence of asymmetric factor, gear profile, pressure angle, gear ratio and the maximum fillet stress on the meshing gears to obtain the optimum design were investigated by V. Senthil Kumar [3] et al. P.B.Pawar et al have developed Al metal matrix composite spur gear using stir casting machine. All the mechanical tests were taken and concluded that stress dissemination is obtained through FEM shows maximum stress at tip of the teeth [4]. Seok-Chul Hwang [5] et al, this project deals with the contact stress analysis of gear pair at mating point. This study deals with the contact stress analysis of spur and helical gear based on the contact position. Two dimensional FEM analysis was performed on spur gear, while $3 \mathrm{D}$ analysis was done on helical gears. Vivek Karaveer et al have done modeling and FEM analysis of spur gear on grey cast iron and steel. FEM results are compared with analytical Hertzian equation[6]. Ali Raad Hassan has done a research on contact stress analysis of spur gear at various mating positions. A programme was developed to make a pair of tooth contact. Each case was represented a sequence position of contact between these two teeth. The programme gives graphical results of each position. Stress analysis was done using FEM model. Both graphical and FEM results are compared. The result revealed that the stress is maximum at beginning and end of the contact and minimum at mating point[7].

In this work, gear trains having no idler gear, one idler gear and two idler gears were modeled using SOLIDWORKS 2016 software. Steel, cast iron, and aluminum alloy are taken as gear materials. Bending and contact stress analysis has been carried out on the gear trains for each materials using ANSYS workbench 14.5 software. Theoretical and FEM results were compared and validated. TATRA off-road vehicle has taken for analysis. 


\section{SELECTION OF GEAR PARAMETERS}

Gear parameters are selected based on the power requirement. Vehicle specification is given in the below table. Gears are designed to the maximum torque value.

Table 1. TATRA vehicle specifications

\begin{tabular}{|l|l|}
\hline Vehicle & Tatra T810 \\
\hline Power & $177 \mathrm{KW}$ \\
\hline Max Torque & $820 \mathrm{~N}-\mathrm{m}$ \\
\hline Speed Range & 1220 to $2300 \mathrm{rpm}$ \\
\hline Pay Load & $4500 \mathrm{Kg}$ \\
\hline Ground Clearance & $460 \mathrm{~mm}$ \\
\hline
\end{tabular}

Initially, number of teeth in gear is 20 and pressure angle is $20^{\circ}$ has taken to avoid interference.

Velocity $\mathrm{V}=\frac{\pi \mathrm{DN}}{60}=\frac{\pi * \mathrm{M} * 20 * 2300}{60}=2.4 \mathrm{M} \mathrm{m} / \mathrm{sec}$ (1)

Tangential Force $\mathrm{Ft}=\frac{1000 \mathrm{P}}{\mathrm{V}} \mathrm{Cs}$

$\mathrm{Ft}=\sigma * \mathrm{Cv} * \mathrm{~b} * \mathrm{M} * \mathrm{y} * \pi$

Module $\mathrm{M}=6 \mathrm{~mm}$

All other parameters are calculated based on the module. Both gear and pinion are rotating at the same speed. Hence the speed ratio is 1 . Number of teeth on gear and pinion are equal. Shaft hole diameter has taken as $30 \mathrm{~mm}$ to apply the boundary conditions and load. Involute, full depth spur gear is chosen for analysis.

Table 2. Gear Specifications

\begin{tabular}{|l|l|l|}
\hline Parameters & Formula & Values \\
\hline Face Width, b (mm) & $10 \mathrm{M}$ & 60 \\
\hline Pitch Circle Diameter, $\mathrm{p}_{\mathrm{c}}(\mathrm{mm})$ & $2 \mathrm{M}$ & 120 \\
\hline Diametrical Pitch, $\mathrm{p}_{\mathrm{d}}\left(\mathrm{mm}^{-1}\right)$ & $1 / \mathrm{M}$ & 0.166 \\
\hline Addendum, a (mm) & $\mathrm{M}$ & 6 \\
\hline Dedendum, d (mm) & $1.25 \mathrm{M}$ & 7.5 \\
\hline Tooth Thickness, T (mm) & $1.5708 \mathrm{M}$ & 9.42 \\
\hline Centre distance, C $(\mathrm{mm})$ & $2 \mathrm{~b}$ & 120 \\
\hline
\end{tabular}

\section{MODELING OF GEAR TRAIN}
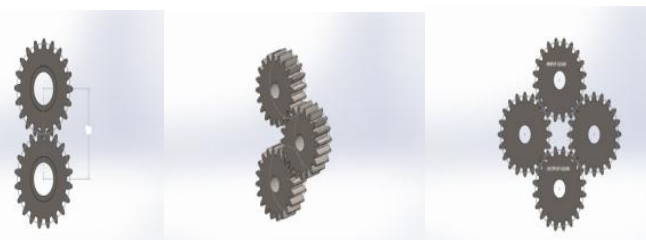

Figure 2. Assembly model of gear trains [9]
In this analysis, the gears are assigned with three different materials. The mechanical properties of each material as shown in table.3.

Table 3. Properties of gear materials

\begin{tabular}{|l|c|c|c|}
\hline Properties & Steel & $\begin{array}{c}\text { Cast } \\
\text { Iron }\end{array}$ & $\begin{array}{c}\text { Aluminium } \\
\text { Alloy }\end{array}$ \\
\hline Density $\left(\mathrm{Kg} / \mathrm{mm}^{3}\right)$ & 7800 & 7100 & 2770 \\
\hline Poission's ratio & 0.3 & 0.28 & 0.33 \\
\hline Elastic constant $\left(\mathrm{N} / \mathrm{mm}^{2}\right)$ & $2.1 * 105$ & $1.1 * 105$ & $0.71 * 105$ \\
\hline Yield Strength $\left(\mathrm{N} / \mathrm{mm}^{2}\right)$ & 250 & 195 & 280 \\
\hline Ultimate Strength $\left(\mathrm{N} / \mathrm{mm}^{2}\right)$ & 460 & 240 & 310 \\
\hline
\end{tabular}

\section{STATIC STRESS ANALYSIS}

Bending and contact stress analysis was done on all the three configurations using FEM with three different materials.

\section{Bending Stress Using Lewis Equation}

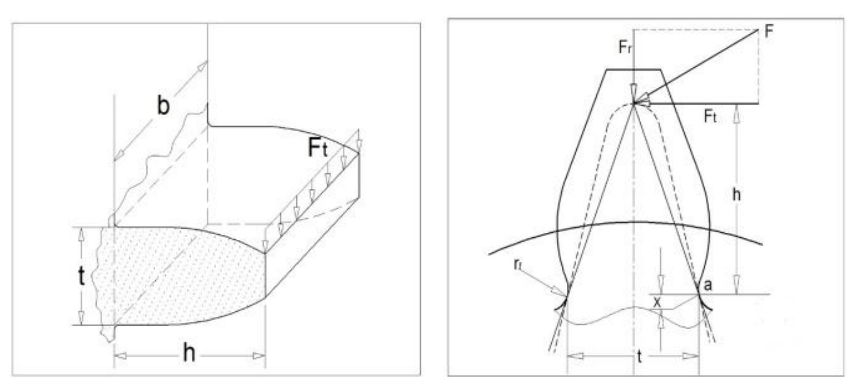

Figure 3. Forces acting on gear tooth

The conventional analytical method to calculate bending stress in a gear tooth is the Lewis equation. It states that, a gear tooth is subjected to the full load at its tip and act as a cantilever beam.

$$
\text { Bending Stress } \sigma=\frac{\mathrm{Ft}}{\mathrm{by \textrm {M }}}
$$

Where,

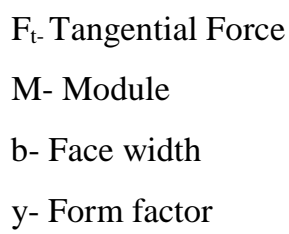

\section{Bending Stress Using FEM}

Gear train for three configurations was modeled and imported to ANSYS workbench. Tetrahedron element has been chosen during meshing of gear train. The two meshing gears are identical and the single point tooth contact was ensured. 

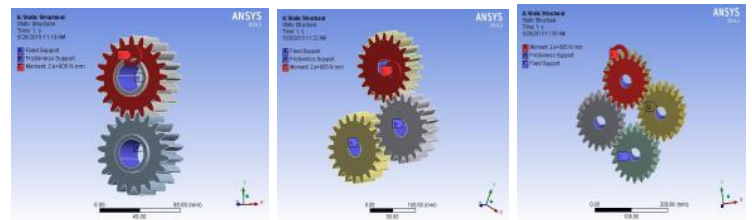

Figure.5: Boundary conditions for bending stress analysis

Meshing was done carefully at root fillet of the gear to estimate the critical bending stress with element size is $1 \mathrm{~mm}$. Input gear is assumed as frictionless support and output gear is fixed support. A moment of $200 \mathrm{~N}-\mathrm{m}$ to $1000 \mathrm{~N}-\mathrm{m}$ was applied to the shaft of the input gear.

\section{Hertz Contact Stress}

Pitting is one of the gear tooth failures occurs on its surface caused by repetitive fatigue load. Contact stress is developed at pitch point of mating gears. The contour of contcact surfaces is in the form of an ellipse. Contact stress at the mating point is calculated by Hertz contact stress theory. Figure. 6 shows the contact between two mating cylinders.

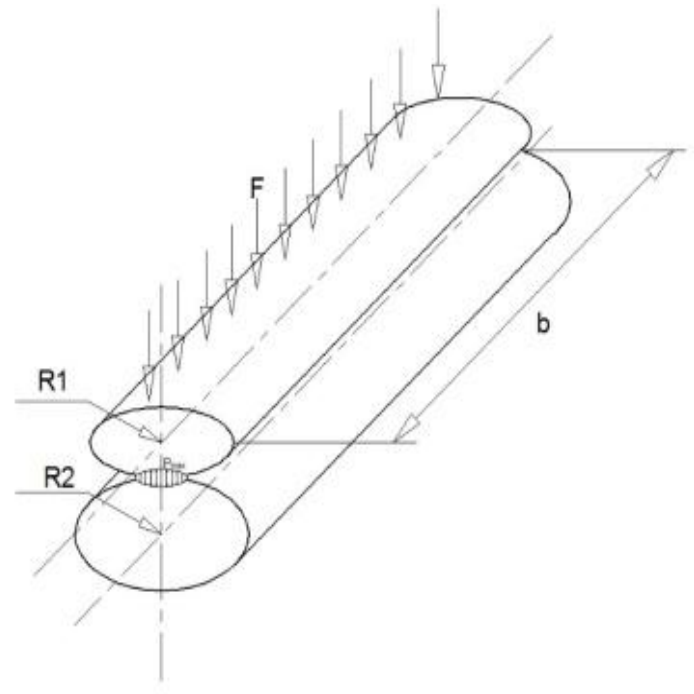

Figure. 6. Contact between two cylinders
Based on the theory,

Contact Stress $\sigma=\sqrt{\frac{F\left(\frac{1}{R 1}+\frac{1}{R 2}\right)}{b \pi\left[\frac{1-\vartheta 1^{2}}{E 1}+\frac{1-\vartheta 2^{2}}{E 2}\right]}}$

where,
F- Force applied on the cylinder
$\mathrm{R}_{1}, \mathrm{R}_{2}$ - Radius of cylinder 1 and 2
b- Face width
$\mathrm{E}_{1}, \mathrm{E}_{2}-$ Elastic constant of cylinder 1 and 2
$v_{1}, v_{2}-$ Poission's ration of cylinder 1 and 2

\section{Contact Stress Using FEM}

For contact stress analysis, frictional contact was assigned. Augmented Lagrange was selected as the solver. The input gear was treated as 'Contact' and the output gear was treated as 'Target'. Both the gears are assigned with frictionaless support to get pure rotation.
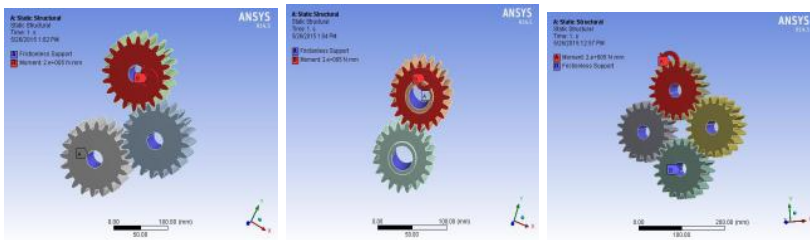

Figure.7: Boundary conditions for contact stress analysis

\section{FEM RESULTS AND VALIDATION}

\section{Lewi's Bending Stress}

$$
\begin{aligned}
& \text { Bending Stress } \sigma=\frac{\mathrm{Ft}}{\mathrm{b} \mathrm{YM}} \\
& \mathrm{Ft}=2 \mathrm{Mt} / \mathrm{Pc} \\
& \mathrm{F}_{\mathrm{t}}=\frac{200000 * 2}{120}=3333.33 \mathrm{~N} \\
& \sigma=\frac{3333.33}{60 * 0.32 * 6}=28.93 \mathrm{~N} / \mathrm{mm}^{2}
\end{aligned}
$$

\section{FEM Bending Stress}
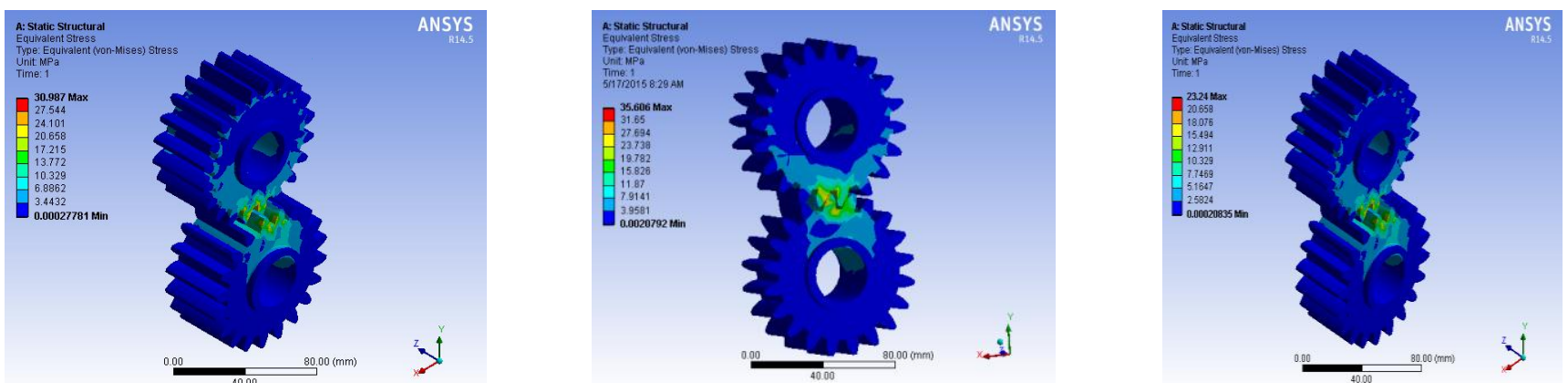

Figure. 8: Without idler gear for Steel, CI and Al alloy 

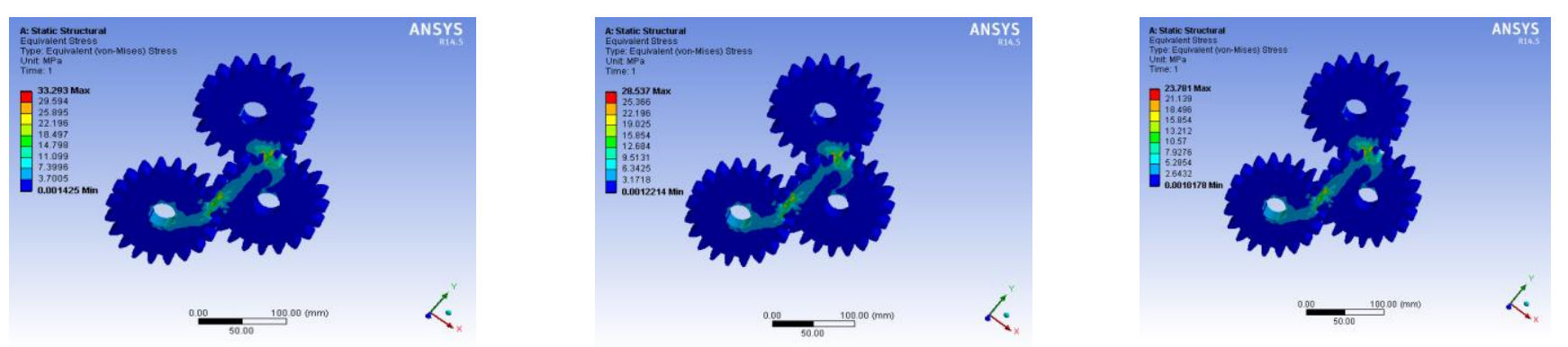

Figure. 9: With one idler gear for Steel, CI and Al alloy
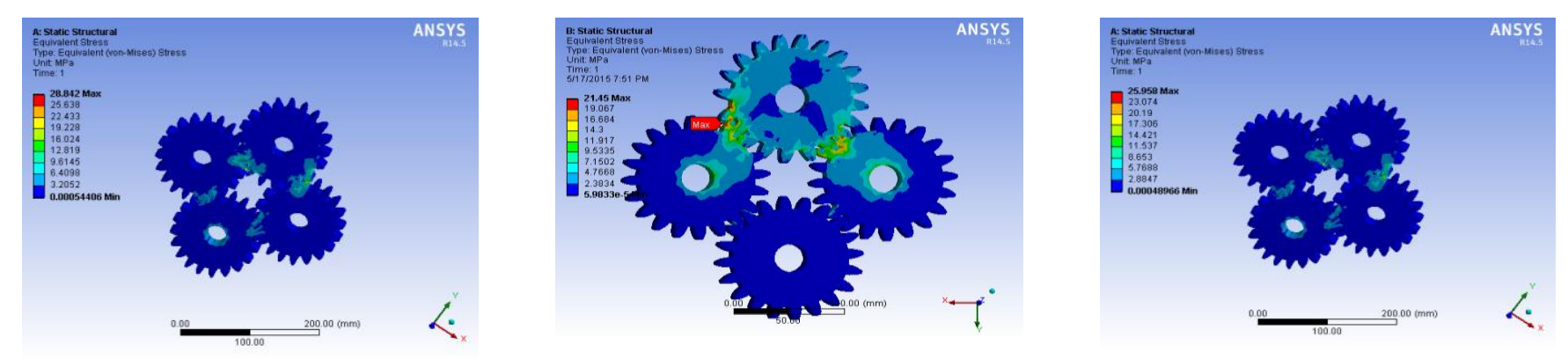

Figure. 10: With two idler gear for Steel, CI and Al alloy

Table 4. FEM and Lewi's bending stress

\begin{tabular}{|c|c|c|c|c|c|c|c|c|c|c|}
\hline \multirow{2}{*}{$\begin{array}{c}\text { Torque } \\
(\mathbf{N}-\mathbf{m})\end{array}$} & \multirow{2}{*}{ Lewi's Stress (Mpa) } & \multicolumn{2}{|c|}{ Without Idler Gear (MPa) } & \multicolumn{2}{|c|}{ With One Idler Gear (MPa) } & \multicolumn{3}{|c|}{ With Two Idler Gear (MPa) } \\
\cline { 2 - 12 } & & Steel & CI & Al alloy & Steel & CI & Al alloy & Steel & CI & Al alloy \\
\hline 200 & 28.93 & 30.98 & 35.60 & 23.24 & 28.55 & 33.29 & 23.78 & 25.95 & 28.84 & 21.45 \\
\hline 400 & 57.86 & 53.03 & 61.67 & 49.99 & 53.40 & 56.67 & 52.68 & 52.02 & 55.56 & 50.60 \\
\hline 600 & 86.8 & 84.14 & 88.79 & 80.58 & 82.12 & 84.79 & 80.30 & 80.15 & 82.23 & 78.32 \\
\hline 800 & 115.7 & 107.18 & 127.24 & 103.18 & 104.18 & 117.24 & 100.90 & 101.18 & 114.43 & 97.45 \\
\hline 1000 & 144.65 & 133.56 & 153.43 & 127.37 & 124.56 & 131.43 & 117.15 & 120.71 & 127.40 & 112.84 \\
\hline
\end{tabular}

FEM and Lewi's bending stress for all gear configurations on three materials is shown in table 4.

\section{Hertz Contact Stress}

For $\mathrm{M}_{\mathrm{t}}=200 \mathrm{~N}-\mathrm{m}$

$\mathrm{F}=3333.33 \mathrm{~N}$

$$
\sigma=\sqrt{\frac{W\left(\frac{1}{R 1}+\frac{1}{R 2}\right)}{b \pi\left[\frac{1-\vartheta 1^{2}}{E 1}+\frac{1-\vartheta 2^{2}}{E 2}\right]}}
$$

For Steel $\quad \sigma=\sqrt{\frac{3333.33\left(\frac{1}{60}+\frac{1}{60}\right)}{\pi * 60 *\left(\frac{1-0.3^{2}}{2 * 10^{5}}+\frac{1-0.3^{2}}{2 * 10^{5}}\right)}} \quad=250.85 \mathrm{~N} / \mathrm{mm}^{2}$ For Cast Iron $\sigma=\sqrt{\frac{3333.33\left(\frac{1}{60}+\frac{1}{60}\right)}{\pi * 60 *\left(\frac{1-0.28^{2}}{1.1 * 10^{5}}+\frac{1-0.28^{2}}{1.1 * 10^{5}}\right)}}=187.55 \mathrm{~N} / \mathrm{mm}^{2}$ For Aluminium Alloy $\sigma=\sqrt{\frac{3333.33\left(\frac{1}{60}+\frac{1}{60}\right)}{\pi * 60 *\left(\frac{1-0.33^{2}}{0.7 * 10^{5}}+\frac{1-0.33^{2}}{0.7 * 10^{5}}\right)}}=153.2 \mathrm{~N} / \mathrm{mm}^{2}$ 


\section{FEM contact stress}
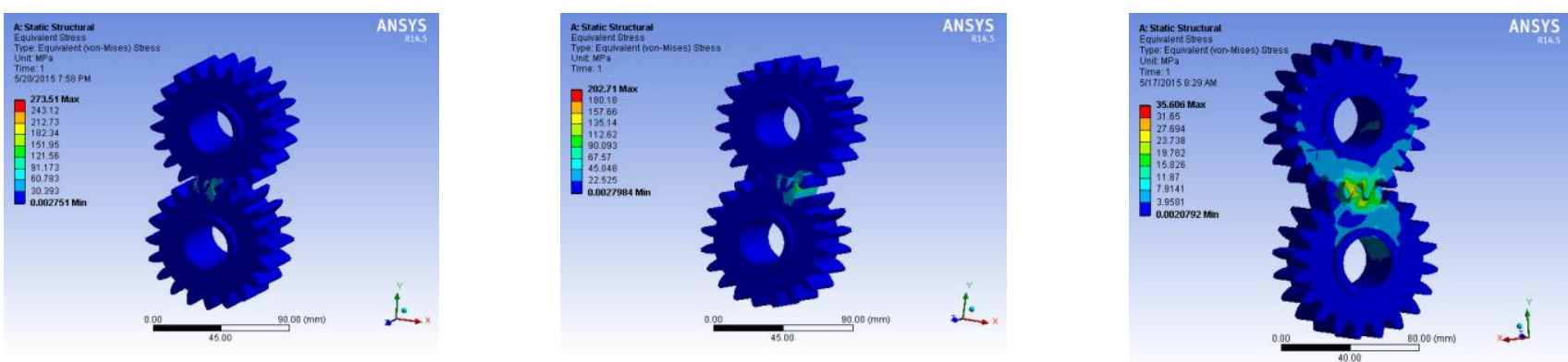

Figure. 11: Without idler gear for Steel, $\mathrm{CI}$ and $\mathrm{Al}$ alloy

Table 5. FEM and Hertz contact stress for without ideal gear

\begin{tabular}{|l|l|l|l|l|l|l|}
\hline \multirow{2}{*}{$\begin{array}{l}\text { Torque } \\
(\mathbf{N}-\mathbf{l})\end{array}$} & \multicolumn{2}{l}{ Steel (Mpa) } & \multicolumn{2}{l|}{ CI (Mpa) } & Al alloy (Mpa) \\
\cline { 2 - 7 } & FEA & HERTZ & FEA & HERTZ & FEA & HERTZ \\
\hline 200 & 273.51 & 250.85 & 197.6 & 187.55 & 166.30 & 153.2 \\
\hline 400 & 376.08 & 355.33 & 286.23 & 265.60 & 226.71 & 216.75 \\
\hline 600 & 410.27 & 435.19 & 340.52 & 325.35 & 280.01 & 265.46 \\
\hline 800 & 547.03 & 502.51 & 393.76 & 375.62 & 329.58 & 306.5 \\
\hline 1000 & 581.22 & 561.83 & 442.34 & 419.95 & 360.49 & 342.7 \\
\hline
\end{tabular}
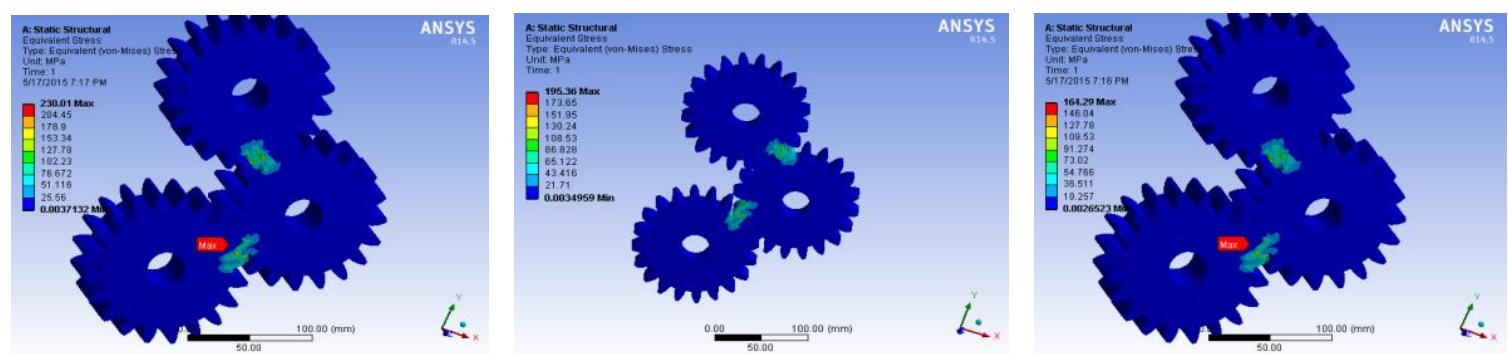

Figure. 12: With one idler gear for Steel, $\mathrm{CI}$ and $\mathrm{Al}$ alloy

Table 6. FEM and Hertz contact stress for with one ideal gear

\begin{tabular}{|c|c|c|c|c|c|c|}
\hline \multirow{2}{*}{$\begin{array}{c}\text { Torque } \\
(\mathbf{N}-m)\end{array}$} & \multicolumn{2}{|c|}{ Steel (Mpa) } & \multicolumn{2}{c|}{ CI (Mpa) } & \multicolumn{2}{c|}{ Al alloy (Mpa) } \\
\cline { 2 - 7 } & FEA & HERTZ & FEA & HERTZ & FEA & HERTZ \\
\hline 200 & 230.01 & 250.85 & 195.36 & 187.55 & 164.26 & 153.2 \\
\hline 400 & 323.45 & 355.33 & 269.34 & 265.60 & 212.41 & 216.75 \\
\hline 600 & 390.64 & 435.19 & 323.54 & 325.35 & 264.54 & 265.46 \\
\hline 800 & 540.30 & 502.51 & 372.56 & 375.62 & 302.88 & 306.5 \\
\hline 1000 & 562.32 & 561.83 & 422.14 & 419.95 & 334.40 & 342.7 \\
\hline
\end{tabular}



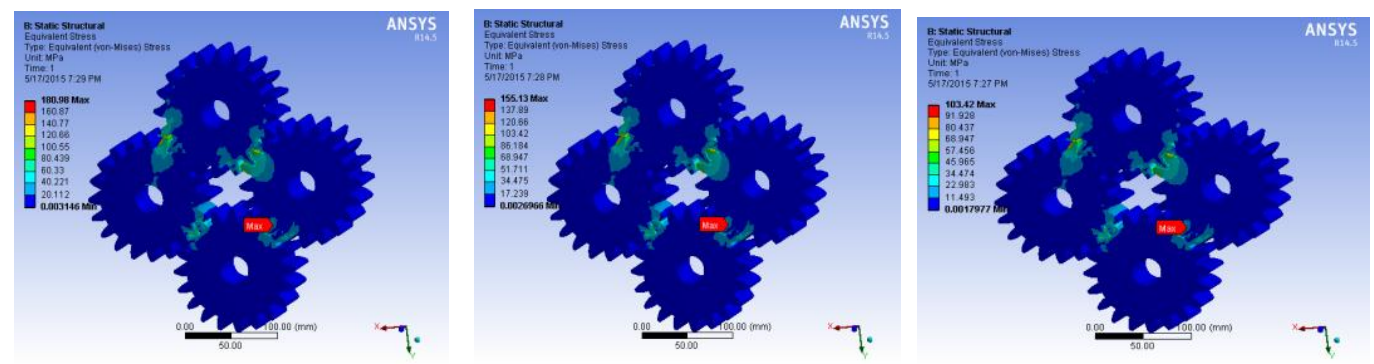

Figure. 13: With two idler gear for Steel, CI and Al alloy

Table 7. FEM and Hertz contact stress for with two ideal gear

\begin{tabular}{|c|c|c|c|c|c|c|}
\hline \multirow{2}{*}{$\begin{array}{c}\text { Torque } \\
(\mathbf{N}-m)\end{array}$} & \multicolumn{2}{|c|}{ Steel (Mpa) } & \multicolumn{2}{c|}{ CI (Mpa) } & \multicolumn{2}{c|}{ Al alloy (Mpa) } \\
\cline { 2 - 7 } & FEA & HERTZ & FEA & HERTZ & FEA & HERTZ \\
\hline 200 & 190.45 & 250.85 & 155.36 & 187.55 & 103.26 & 153.2 \\
\hline 400 & 273.44 & 355.33 & 225.94 & 265.60 & 187.14 & 216.75 \\
\hline 600 & 300.39 & 435.19 & 293.56 & 325.35 & 204.32 & 265.46 \\
\hline 800 & 510.08 & 502.51 & 332.55 & 375.62 & 278.86 & 306.5 \\
\hline 1000 & 520.35 & 561.83 & 402.11 & 419.95 & 285.70 & 342.7 \\
\hline
\end{tabular}

\section{CONCLUSION}

Bending and contact stresses are confirmed by comparing theoretical results with FEA. Both results are matched with a difference of 4-12\% on average. The comparison was made on gear trains with three different materials. Gear train having two idler gears experiences less stress compared to other two configurations. Gear train with idler gears provides $50 \mathrm{~mm}$ more ground clearance than the gear train without idler gear. In contact stress analysis, Cast iron shows $20-25 \%$ of reduction stress values and aluminium alloy shows $30-40 \%$ reduction in stress values compared to steel. Also aluminium alloy has 50-60\% reduction in weight of the system.

\section{REFERENCES}

[1] Qin, W. J., and C. Y. Guan. An investigation of contact stresses and crack initiation in spur gears based on finite element dynamics analysis. International Journal of Mechanical Sciences83 (2014): 96-103.

[2] Shuting Li. Finite element analyses for contact strength and bending strength of a pair of spur gears with machining errors, assembly errors and tooth modifications. Mechanism and Machine Theory, 42(1), 88-114.

[3] V. Senthil Kumar, D.V. Muni, G. Muthuveerappan. Optimization of asymmetric spur gear drives to improve the bending load capacity. 10.1016/j.mechmachtheory.2007.06.006. Mechanism and Machine Theory 43 (2008) 829-858.

[4] P.B.Pawar, Abhay A. Utpat, Development of Aluminium Based Silicon Carbide Particulate Metal Matrix Composite for Spur Gear. doi:10.1016/j.mspro.2014.07.187. Procedia Materials Science 6 ( 2014 ) 1150 - 1156.

[5] Seok-Chul Hwanga, Jin-Hwan Lee b, Dong-Hyung Lee. Contact stress analysis for a pair of mating gears. doi:10.1016/j.mcm.2011.06.055. Mathematical and Computer Modelling 57 (2013) 40-49.

[6] Vivek KaraveerÁ, Ashish Mogrekar and T. Preman Reynold Joseph. Modeling and Finite Element Analysis of Spur Gear. International Journal of Current Engineering and Technology.ISSN 2277 4106.

[7] Ali Raad Hassan, Contact Stress Analysis of Spur Gear Teeth Pair. World Academy of Science, Engineering, and Technology, Vol:3 2009-10-20.

[8] JongBoon Ooi, Xin Wang, ChingSeong Tan, JeeHou Ho and Ying Pio Lim. Modal and stress analysis of gear train design in portal axle using finite element modeling and simulation. Journal of Mechanical Science and Technology 26 (2) (2012) 575 589.

[9] Miryam B. Sánchez, Miguel Pleguezuelos, José I. Pedrero. Approximate equations for the meshing stiffness and the load sharing ratio of spur gears including Hertzian effects. Mechanism and Machine Theory. Volume 109, March 2017, Pages 231-249.

[10] Newton K. Fukumasu, Guilherme A.A. Machado, Roberto M. Souza, Izabel F. Machado. Stress Analysis to Improve Pitting Resistance in Gear Teeth. Procedia CIRP, Volume 45, 2016, Pages 255258. doi.org/10.1016/j.procir.2016.02.349. 
International Journal of Applied Engineering Research ISSN 0973-4562 Volume 13, Number 7 (2018) pp. $5244-5250$

(C) Research India Publications. https://dx.doi.org/10.37622/IJAER/13.7.2018.5244-5250

[11] S. Jyothirmai, R. Ramesh, T. Swarnalatha, D. Renuka. A Finite Element Approach to Bending, Contact and Fatigue Stress Distribution in Helical Gear Systems. Procedia Materials Science, Volume 6, 2014, Pages 907-918.

[12] Edoardo Conrado, Carlo Gorla, Piermaria Davoli, Marco Boniardi. A comparison of bending fatigue strength of carburized and nitrided gears for industrial applications. Engineering Failure Analysis. Volume 78, August 2017, Pages 41-54.

[13] Toni Jabbour, Ghazi Asmar . Tooth stress calculation of metal spur and helical gears. Mechanism and Machine Theory, Volume 92, October 2015, Pages 375-390.

[14] Miryam B. Sánchez, José I. Pedrero, Miguel Pleguezuelos. Critical stress and load conditions for bending calculations of involute spur and helical gears. International Journal of Fatigue Volume 48, March 2013, Pages 28-38 